\title{
International electives in neurological surgery training: a survey of program directors from Accreditation Council for Graduate Medical Education-approved neurological surgery programs
}

\author{
Christopher Miller, MD, ${ }^{1}$ Paige Lundy, MD, ${ }^{1}$ and Sarah Woodrow, MD, MEd, FRCS(C) ${ }^{2}$ \\ ${ }^{1}$ Department of Neurological Surgery, University of Kansas, Kansas City, Kansas; and ²Department of Neurological Surgery, \\ Cleveland Clinic, Akron, Ohio
}

\begin{abstract}
OBJECTIVE The burden of neurosurgical disease in low- and middle-income countries (LMICs) has emerged as a significant factor in global health. Additionally, calls have been growing for first-world neurosurgeons to find ways to help address the international need. Allowing residents to pursue international elective opportunities in LMICs can help alleviate the burden while also providing unique educational opportunities. However, pursuing international work while in residency requires overcoming significant logistical and regulatory barriers. To better understand the general perspectives, perceived barriers, and current availability of international rotations, a survey was sent out to program directors at Accreditation Council for Graduate Medical Education (ACGME)-approved residencies.
\end{abstract}

METHODS An anonymous survey was sent to all program directors at ACGME-approved residencies. The survey included branch points designed to separate programs into program directors with an existing international rotation, those interested in starting an international rotation, and those not interested in starting an international rotation. All participants were asked about the perceived value of international training and whether residents should be encouraged to train internationally on a 5-point Likert scale. The survey ended with open-response fields, encouraging thoughts on international rotations and overcoming barriers.

RESULTS Forty-four percent of recipients (50/113) responded; of the 50 programs, 13 had an established international elective. Of programs without a rotation, $54 \%(20 / 37)$ noted that they were interested in starting an international elective. Key barriers to starting international training included funding, the Residency Review Committee approval process, call conflicts, and the establishment of international partners. Perceived learning opportunities included cultural awareness, unique pathology, ingenuity, physical examination skills, and diagnosis skills. The majority of respondents thought that international rotations were valuable $(74 \%, 37 / 50)$ and that residents should be encouraged to pursue international educational opportunities $(70 \%, 35 / 50)$. Program directors who maintained an existing international rotation or were interested in starting an international elective were more likely to perceive international rotations as valuable.

CONCLUSIONS Recent calls from The Lancet Commission on Global Surgery for increased surgical interventions in the developing world have been expanded by neurosurgical leadership to include neurosurgical diseases. Resident involvement in international electives represents an opportunity to increase treatment of neurosurgical disease in LMICs and develop the next generation of international neurosurgeons. To increase opportunities for residents at international sites, attention should be focused on overcoming the practical and regulatory barriers at a local and national level.

https://thejns.org/doi/abs/10.3171/2020.4.JNS20618

KEYWORDS international electives; resident education; resident training; global neurosurgery

$\mathrm{G}$ ROWING evidence in the neurosurgical literature regarding needs and opportunities in low- and middle-income countries (LMICs) challenges the notion that neurosurgery is limited to the "first world." Recent data have demonstrated that the yearly disease burden in LMICs requiring neurosurgical expertise is estimated to affect 17.5 million patients, 10.7 million of whom require surgery. Due to an estimated deficit of 23,318 providers worldwide, 5.1 million patients, primarily in LMICs, go without needed neurosurgical care. ${ }^{1}$ Neurotrauma patients

ABBREVIATIONS ACGME = Accreditation Council for Graduate Medical Education; LMIC = low- and middle-income country; RRC = Residency Review Committee. SUBMITTED February 29, 2020. ACCEPTED April 20, 2020.

INCLUDE WHEN CITING Published online July 10, 2020; DOI: 10.3171/2020.4.JNS20618. 
require a disproportionate amount of this care, as it has been estimated that traumatic brain injury affects 50 million people per year in these countries. ${ }^{2}$ Even when care is accessible, clinical outcomes may be suboptimal compared with those in higher-income countries. Xu et al., for example, reported that the 1-year mortality rate for neural tube closure defects was $34 \%$ at one Ugandan hospital compared with $6.4 \%$ in the US. ${ }^{3}$ Although addressing this deficit is formidable, neurosurgery as a field should seek opportunities to alleviate the disease burden in LMICs.

A truly impactful intervention in these countries needs to be consistent and include the development of programs and practitioners. ${ }^{4-6}$ Moreover, such programs should be thoughtfully embedded in a larger framework that incorporates a more comprehensive approach to improving surgical care, one that includes consideration of not just workforce but also other factors, such as financing and infrastructure. ${ }^{7}$ In order to begin addressing these needs, a significant surgical workforce from high-income nations would be necessary to provide long-term and consistent aid. Creating an effective neurosurgical workforce entails early experience and education in the unique elements of working in LMICs.

Studies across surgical specialties, including neurosurgery, have demonstrated residents' significant interest in training in LMICs. ${ }^{8-13}$ Training, however, is not without significant barriers, including funding, approval by accrediting institutions, allowing time away from home training, finding appropriate training locations, and receiving academic recognition. , $^{4-16}$ Reducing the barriers to foster training in these environments would allow interested residents to train at an early point in their career and develop the necessary knowledge base and skills to continue as a member of the international surgical workforce throughout their career.

The individual at any given US training program most responsible for resident education is the program director. Therefore, a strong understanding of their opinions on exposure to LMIC environments is crucial to understand and expand this type of resident training. To do this, program directors at Accreditation Council for Graduate Medical Education (ACGME)-approved training sites were surveyed. Through these data, a better understanding of international training in regard to perceived value, opportunities, and barriers can be used to introduce changes to improve early international training and ultimately the global neurosurgical workforce.

\section{Methods}

This study was reviewed and qualified for exempt status by the University of Kansas institutional review board.

An anonymous internet-based questionnaire was developed and distributed using our university's REDCap database. The survey was distributed initially to program coordinators of ACGME-accredited neurological surgery programs with a request to complete the survey with their program directors. Nonresponding coordinators were contacted 1 additional time. Following this, the same survey was distributed 2 more times directly to program directors at nonresponding programs. Participants were asked a to- tal of 10 to 15 questions depending on their responses to branching questions (Supplemental Figure A).

Baseline demographic information regarding the respondent's residency program was collected, including self-identification of region (Northeast, Southeast, Midwest, South, Northwest, or Southwest), number of residents, and number of faculty. No specific information was asked that could match a survey participant to a specific program.

Participants were asked if their program offered training opportunities in developing countries and, if they did not have a program, whether they were interested in starting an international elective. These questions were used as branch points. Those with international electives were asked logistical questions about the elective. Participants without a program but with interest in starting a program were asked about perceived barriers for establishing an international elective. Using a 5-point Likert scale, all participants were asked 2 questions about perceived values of international rotations and whether residents should be encouraged to participate in international rotations. The survey concluded with open-response questions encouraging opinions on international rotations and opportunities for overcoming barriers. Please see Supplemental Figure A for full detail.

All data were analyzed using SPSS (version 25, IBM Corp.). Descriptive statistics were used for the initial analysis. Group comparisons were done using the Mann-Whitney U-test to compare Likert scale responses between those participants who responded yes or no to having an international rotation and having the desire to start an international rotation.

\section{Results}

Of 113 targeted ACGME-approved programs, 50 responded, for a response rate of $44.2 \%$. Responses were obtained from all geographic regions in the US, resident complement sizes, and faculty sizes (Table 1). Of the 50 program directors who responded to the survey, $13(26 \%)$ reported having an international elective available. Training locations were in LMICs for 9 programs and high-income countries for 3; no country was noted for 1 program. Rotation length ranged from 1 to 9 weeks or more and typically occurred during the 5th year of residency (Table 2). Rotation experiences typically included clinical and research; an additional program noted international collaboration with other residents. Time was allotted through a combination of an ACGME-approved elective (5/13), research time (4/13), vacation time (3/13), professional time (paid leave not counting toward vacation or sick leave; $2 / 13)$, or elective time (1/13). Funding came from a variety of sources, including the department (10/13), fundraising $(3 / 13)$, resident out of pocket $(3 / 13)$, private $(4 / 13)$, and funding from the destination site $(1 / 13)$.

Of the 37 program directors without an international rotation, $20(54.1 \%)$ noted that they were interested in starting one. The program directors interested in starting an international rotation noted funding (19/20), Residency Review Committee (RRC) approval process (12/20), call conflicts (10/20), and establishing international partners 
TABLE 1. Demographics of all survey respondents

\begin{tabular}{cc}
\hline \multicolumn{2}{c}{ No. of Respondents $(\%)$} \\
\hline Program location \\
\hline Northeast & $16(32)$ \\
\hline Southeast & $9(18)$ \\
\hline Midwest & $16(32)$ \\
\hline South & $3(6)$ \\
\hline Northwest & $1(2)$ \\
\hline Southwest & $5(10)$ \\
\hline Resident complement & $6(12)$ \\
\hline $1-7$ & $14(28)$ \\
\hline $8-13$ & $21(42)$ \\
\hline $14-20$ & $9(18)$ \\
\hline$\geq 21$ & \\
\hline Staff size & $19(38)$ \\
\hline $1-10$ & $20(40)$ \\
\hline $11-20$ & $11(22)$ \\
\hline$\geq 20$ &
\end{tabular}

$(10 / 20)$ as the most significant barriers to initiating a rotation (Fig. 1).

Survey participants generally noted value in international rotations (Fig. 2) and, to a lesser degree, that residents should be encouraged to pursue international opportunities for training (Fig. 3). Noted benefits of rotations were cultural awareness (46/50), exposure to unique pathology (33/50), improving ingenuity (33/50), and enhancing physical examination and diagnosis skills (18/50). Only 2 of the 50 participants noted that there was no meaningful benefit to an international rotation.

The survey participants who did not have an existing international rotation $(n=37)$ were separated into 2 groups: those interested in starting an international rotation and those not interested. Our analysis indicates that the perceived value of international rotations was higher for those individuals interested in starting an international rotation (median score 2, agree) than those not interested (median score 3 , neutral $)(U=77, p=0.002)$. Furthermore, when survey participants were grouped into programs with and without international programs, the perceived value of these rotations was higher for those with an international elective (median score 1, strongly agree) and compared with those without an international elective (median score 2 , agree) $(\mathrm{U}=132, \mathrm{p}=0.008)$.

Open-ended response questions resulted in a number of interesting and unique viewpoints and are detailed in Discussion.

\section{Discussion Need}

An increasing number of publications outline the need for expanded surgical care throughout LMICs., ${ }^{2,14,15}$ The Lancet Commission on Global Surgery states that 143 million additional procedures are needed in LMICs, and without these procedures, an estimated 16.9 million lives were lost. ${ }^{17,18}$ Furthermore, the economic burden of surgically
TABLE 2. Demonstrating programs that offer rotations and logistical responses from programs with international electives

\begin{tabular}{cc}
\hline \multicolumn{2}{l}{ No. of Respondents $(\%)$} \\
\hline International elective offered \\
\hline Yes & $13(26)$ \\
\hline No & $37(74)$ \\
\hline Typical rotation length, wks \\
\hline $1-2$ & $6(46)$ \\
\hline $3-4$ & $1(8)$ \\
\hline $5-8$ & $0(0)$ \\
\hline$\geq 9$ & $6(46)$ \\
\hline Most frequent yr of participation & \\
\hline $1-3$ & $0(0)$ \\
\hline 4 & $1(8)$ \\
\hline 5 & $9(69)$ \\
\hline 6 & $1(8)$ \\
\hline 7 & $2(15)$ \\
\hline
\end{tabular}

treatable diseases in LMICs is estimated to result in $\$ 12.3$ trillion in losses between 2015 and 2030. When compared with the estimated cost of scaling up surgical services over the same period ( $\$ 420$ billion), The Lancet Commission ultimately concluded, "Investment in surgical and anesthesia services is affordable, saves lives, and promotes economic growth." ${ }^{17}$ Dewan et al. have already demonstrated cost-effective training programs in LMICs for key pediatric neurosurgical interventions. ${ }^{19}$ This is reinforced by Haglund et al. and their work in Uganda, which has shown the value of "twinning" programs..$^{5}$ In an editorial, Corley and Haglund further reinforced that neurosurgery is no exception to the need for surgical expansion in LMICs as reported by The Lancet Commission. ${ }^{20}$

\section{Value}

The value of international electives in LMICs can be reciprocal; while the visiting resident benefits by learning how to adapt to varied pathologies in resource-limited environments, the underserved site benefits from enhanced academic collaboration and knowledge translation, thereby potentially increasing surgical capacity. ${ }^{.}$

Learners have been noted to develop unique skills in diagnosis and adaptability. ${ }^{21,22}$ This is reflected in this survey's responses, with the majority of respondents acknowledging opportunities internationally for exposure to unique pathology, increasing awareness of international healthcare systems and culture, and improving ingenuity and creativity in the context of limited resources. Furthermore, $74 \%$ of respondents agreed or strongly agreed that international electives are of benefit to neurosurgical resident training. Benefits were further expressed by participants in the open-response fields: "Extremely beneficial to those who are able to attend"; "Enhances the human side and awareness of the residents. Gives perspective about organized neurosurgery in the world stage"; and "Strengthens leadership abilities, independent and critical thinking skills in the OR [operating room] and clinical setting."

The benefit for the host countries is seen qualitatively 


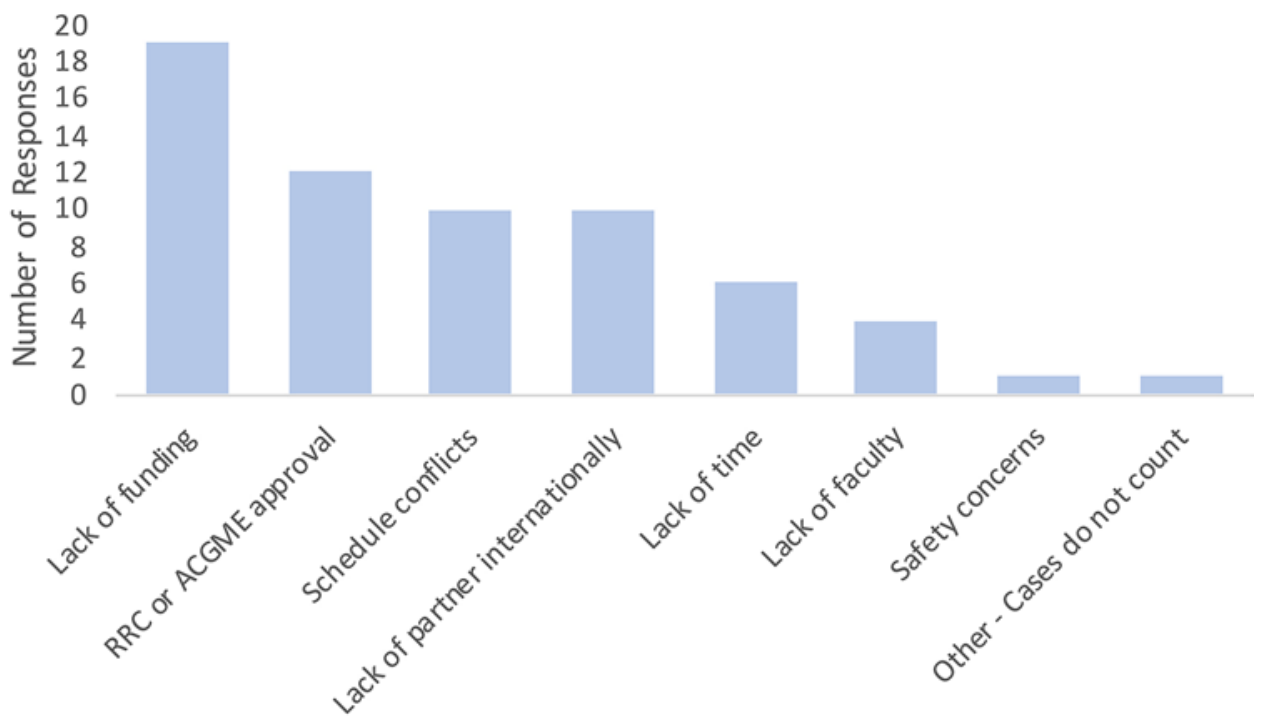

FIG. 1. Bar graph demonstrating the key perceived barriers for program directors interested in starting an international rotation. Figure is available in color online only.

and quantitatively in the literature. , $, 6,23,24$ Almeida et al. pointed out significant concerns of "one-and-done"-type trips that result in immediate benefits but ultimately suffer from a lack of continuity of care, resulting in unattended complications and mistrust from the local inhabitants. ${ }^{4}$ Ideally, long-term partnerships are formed between visiting physicians and host institutions to allow for ongoing collaboration and exchange of knowledge..$^{25,26}$ Residents who participate in international rotations are likely to only participate in 1 or 2 trips during their residency. Although this may seem like a setup for one-and-done-type trips, there is also an opportunity for different residents to travel to the same location with regular staff year after year, thus creating continuity; this is seen with the international neurosurgery programs at Duke University ${ }^{5}$ and the University of Alabama at Birmingham. ${ }^{6}$ While residents are working internationally, it is important for them to understand that they are visitors and should not allow their own development to interfere with that of local trainees. ${ }^{26}$ In this survey, $92 \%$ of participants with international rotations noted that traveling residents were in at least their 5 th

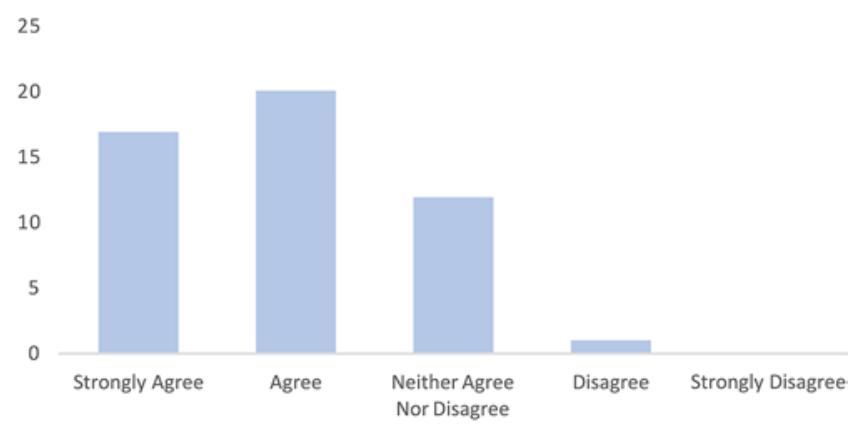

FIG. 2. Bar graph showing the response of all survey participants (y-axis values) regarding the perceived value of international rotations. Figure is available in color online only. year of residency. International training in later years of residency is likely appropriate, as the residents would be better able to focus on developing teaching new skills and technology to local practitioners. ${ }^{26}$ Training and development of residents at international sites allows for a better understanding of the needs of LMICs and, in turn, more confidence in pursuing international work. Ultimately, this increases the likelihood that a given resident will continue to work internationally throughout their career., ${ }^{4,21}$

An interesting finding in this study was the apparent impact of a program director's perceived value of international rotations on the existence and interest in the development of international rotations. The survey asked participants if international rotations are valuable to resident education. Program directors with international rotations and those with interest in starting international rotations were more likely to agree and strongly agree that international rotations have value for resident training. Although this may appear an expected observation, it suggests that the probability of a resident having access to an international rotation through their respective program is subject to the program director's opinions on the value of international rotations.

\section{Barriers}

Program directors were targeted in this study because they are the key persons responsible for coordinating, developing, and maintaining an international rotation for residents at any given program. In turn, they are responsible for navigating the multilayered landscape of barriers that exist for an ACGME-approved program to have an international rotation.

Prior publications have isolated multiple barriers that exist for any practitioner to work internationally. Almeida et al. simplified the barriers into 3 categories: individual, community, and system. ${ }^{4}$ Individual barriers cover the personal feelings of the physician toward international 


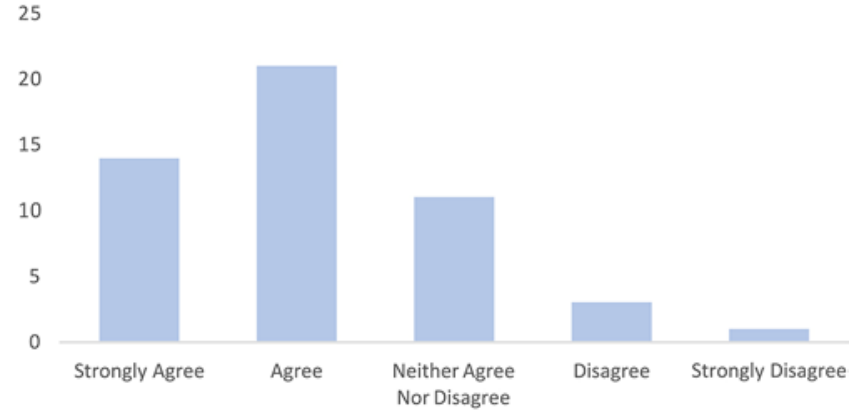

FIG. 3. Bar graph showing the response of all survey participants (y-axis values) regarding whether international training should be encouraged during residency training. Figure is available in color online only.

rotations, including loss of income, concern for value, inexperience, and concern for safety. Community barriers represent a lack of support from colleagues and a lack of mentorship for working internationally. Systemic barriers include funding and lack of professional or academic recognition.

Funding was the principal barrier noted by $95 \%$ of program directors who were interested in starting an international rotation. This coincides with the reality that 10 of 13 programs with an international rotation have some component of funding coming from the department. Funding has also been noted by a number of other publications as a major barrier for professionals interested in international surgery. ${ }^{4,14-16,21}$

This survey highlighted 2 other systemic barriers noted by $50 \%$ of program directors interested in starting a rotation: availability of international training sites and call schedule coverage. Davis et al. noted that $43 \%$ of pediatric neurosurgery respondents had concerns about finding international partners. ${ }^{21}$ They also discussed 29 separate organizations that provide assistance for professionals seeking opportunities in international pediatric neurosurgery; however, the largest groups of respondents noted that they worked without any overseeing agency. For residents who are likely traveling internationally for the first time in a neurosurgical capacity, traveling alone is a major hurdle in regard to finding a site, funding, and ensuring the experience is valuable and safe. ${ }^{27}$ So-called twinning programs have demonstrated significant success. These programs, once established, allow for reciprocal and ongoing benefit with regard to a consistent opportunity for international resident training, exchange of knowledge, and surgical equipment., ${ }^{5,6}$ Unfortunately, for smaller programs, twinning may not be realistic due to a lack of resources. For small programs without the ability for largescale programs there would still need to be a resource for international education sites and a means to address reduced workforce at the home institution. One participant expressed their desire for a more centralized resource to which they could send residents for international experience: "If there were a streamlined program available for any program to send residents to it would facilitate these types of rotations much more effectively."

Looking to larger organizations for international work is a possibility. The strength of North American neuro- surgical organizations represents an opportunity to centralize international opportunities for interested residents in smaller programs. Centralization would provide a resource for residents to seek out international work if their program is unable to start an international program or if their program director is uninterested in developing an international rotation. ${ }^{28}$ Furthermore, a centralized office for international work could focus the funding to create scholarships for interested and deserving residents. ${ }^{29}$

The second most significant barrier, noted by $60 \%$ of program directors interested in starting a rotation, was the ACGME approval process. Three surgical subspecialties have a specific approval process for international rotations: plastic surgery, general surgery, and neurosurgery. Interestingly, the neurosurgical approval process has the highest standards for rotation approval, including significant core faculty involvement. Despite these standards, the RRC for neurological surgery is the only specialty with a specific approval process that does not allow for counting of cases done internationally. ${ }^{30}$ The regulations are important for defining host site selection criteria in order to ensure that any resident experience is educationally valuable and safe. ${ }^{27}$ However, review of the RRC regulations could allow for continued regulation of value and safety but also take into consideration how the regulations could act as barriers to programs establishing and maintaining international rotations. ${ }^{27}$ In this survey, multiple participants expressed their desire for review of the ACGME approval process and consideration of counting cases for credit: "The ABNS [American Board of Neurological Surgery] should consider having the cases logged during international experiences count" and "While we have done this in the past, the current ACGME, GMEC [Graduate Medical Education Committee], and ABNS rules make this laborious and impractical."

To provide equal opportunity for all residents, any reworking of ACGME regulations should allow for programs to start their own international electives, send residents with other ACGME-approved programs, or send residents with centralized organizations.

\section{Limitations}

Respondent bias is likely to be a factor due to the use of a survey to collect data. Those with strong opinions on international rotations and, most likely, those with more positive opinions on international rotations were likely to have been more motivated to respond. Additionally, by targeting program directors, the survey may have missed key individuals at a given institution who deal with international resident training. Furthermore, the scope of this survey did not include directors at existing or potential host institutions, which would be an important perspective for future research. A survey of this nature would also help answer questions related to host site selection, such as which host institutions are appropriate for resident training (i.e., academic vs community based).

\section{Conclusions}

The opportunity to initiate a meaningful change in the landscape of international neurosurgery has never been 
greater. The Lancet Commission on Global Surgery made a bold proclamation regarding surgery in the developing world and the goals for improvement by $2030 .{ }^{17}$ The neurosurgical leadership followed with editorials imploring the neurosurgical community to embrace their potential role in improving international health. ${ }^{2,47,20}$ Transitioning from these proclamations to real changes in international neurosurgical care requires a major shift in the culture of first-world neurosurgical programs to recognize the importance of international work. A key opportunity in changing the neurosurgical culture is at the level of residents. Early opportunities for international work create a foundation of understanding and experience that would be carried throughout an entire career. Generally, residency program directors believe that international electives are valuable to residency training. Although many program directors wish to initiate international programs, there are significant barriers; chief among them are RRC regulations and funding. There are a number of opportunities to overcome these barriers that should be pursued to expand the international experience for ACGME-approved neurosurgical residency programs.

\section{References}

1. Dewan MC, Rattani A, Fieggen G, et al. Global neurosurgery: the current capacity and deficit in the provision of essential neurosurgical care. Executive Summary of the Global Neurosurgery Initiative at the Program in Global Surgery and Social Change. J Neurosurg. 2018;130(4):1055-1064.

2. Dewan MC, Rattani A, Gupta S, et al. Estimating the global incidence of traumatic brain injury. J Neurosurg. 2018;130(4):1080-1097.

3. Xu LW, Vaca SD, He JQ, et al. Neural tube defects in Uganda: follow-up outcomes from a national referral hospital. Neurosurg Focus. 2018;45(4):E9.

4. Almeida JP, Velásquez C, Karekezi C, et al. Global neurosurgery: models for international surgical education and collaboration at one university. Neurosurg Focus. 2018;45(4):E5.

5. Haglund MM, Kiryabwire J, Parker S, et al. Surgical capacity building in Uganda through twinning, technology, and training camps. World J Surg. 2011;35(6):1175-1182.

6. Rocque BG, Davis MC, McClugage SG, et al. Surgical treatment of epilepsy in Vietnam: program development and international collaboration. Neurosurg Focus. 2018;45(4):E3.

7. Corley J, Barthélemy EJ, Lepard J, et al. Comprehensive policy recommendations for head and spine injury care in low- and middle-income countries. World Neurosurg. 2019;132:434-436.

8. LeCompte MT, Goldman C, Tarpley JL, et al. Incorporation of a global surgery rotation into an academic general surgery residency program: impact and perceptions. World J Surg. 2018;42(9):2715-2724.

9. Mohan HM, Fitzgerald E, Gokani V, et al. Engagement and role of surgical trainees in global surgery: Consensus statement and recommendations from the Association of Surgeons in Training. Int J Surg. 2018;52:366-370.

10. Powell AC, Casey K, Liewehr DJ, et al. Results of a national survey of surgical resident interest in international experience, electives, and volunteerism. J Am Coll Surg. 2009;208(2):304-312.

11. Powell AC, Mueller C, Kingham P, et al. International experience, electives, and volunteerism in surgical training: a survey of resident interest. J Am Coll Surg. 2007;205(1):162-168.

12. Lundy P, Miller C, Woodrow S. Current US neurosurgical resident involvement, interest, and barriers in global neurosurgery. Neurosurg Focus. 2020;48(3):E16.

13. Matar WY, Trottier DC, Balaa F, et al. Surgical residency training and international volunteerism: a national survey of residents from 2 surgical specialties. Can J Surg. 2012;55(4):S191-S199.

14. Fallah PN, Bernstein M. Barriers to participation in global surgery academic collaborations, and possible solutions: a qualitative study. J Neurosurg. 2018;130(4):1157-1165.

15. Farmer PE, Kim JY. Surgery and global health: a view from beyond the OR. World J Surg. 2008;32(4):533-536.

16. Park KB, Johnson WD, Dempsey RJ. Global neurosurgery: the unmet need. World Neurosurg. 2016;88:32-35.

17. Meara JG, Leather AJ, Hagander L, et al. Global Surgery 2030: evidence and solutions for achieving health, welfare, and economic development. Lancet. 2015;386(9993):569624.

18. Shrime MG, Bickler SW, Alkire BC, Mock C. Global burden of surgical disease: an estimation from the provider perspective. Lancet Glob Health. 2015;3(suppl 2):S8-S9.

19. Dewan MC, Onen J, Bow H, et al. Subspecialty pediatric neurosurgery training: a skill-based training model for neurosurgeons in low-resourced health systems. Neurosurg Focus. 2018;45(4):E2.

20. Corley JA, Haglund M. Letter: How neurosurgery fits into the Global Surgery 2030 agenda. Neurosurgery. 2016;79(4):E544-E545.

21. Davis MC, Rocque BG, Singhal A, et al. State of global pediatric neurosurgery outreach: survey by the International Education Subcommittee. J Neurosurg Pediatr. 2017;20(2):204210.

22. Rocque BG, Lam S. A case for international neurosurgical experience: US resident experiences with pediatric spinal dysraphism cases. Neurol Res. 2014;36(10):903-905.

23. Daniels AH. International rotations during residency: spine deformity surgery in Ghana. Rhode Island Med J. 2013;96(5):15-17.

24. Warf BC, Campbell JW. Combined endoscopic third ventriculostomy and choroid plexus cauterization as primary treatment of hydrocephalus for infants with myelomeningocele: long-term results of a prospective intent-to-treat study in 115 East African infants. J Neurosurg Pediatr. 2008;2(5):310316.

25. Contini S. Surgery in developing countries: why and how to meet surgical needs worldwide. Acta Biomed. 2007;78(1):4-5.

26. Leow JJ, Kingham TP, Casey KM, Kushner AL. Global surgery: thoughts on an emerging surgical subspecialty for students and residents. J Surg Educ. 2010;67(3):143-148.

27. Miller C, Lundy PA, Woodrow S. The impact of regulation on resident international experiences: a multispecialty review of current ACGME and RRC standards for international electives. J Surg Educ. 2019;76(6):1588-1593.

28. Operation Giving Back. American College of Surgeons. Accessed May 6, 2020. http://www.operationgivingback.facs.org

29. Aarabi S, Smithers C, Fils MM, et al. Global Surgery Fellowship: a model for surgical care and education in resourcepoor countries. J Pediatr Surg. 2015;50(10):1772-1775.

30. ACGME Review Committee for Neurological Surgery. Frequently asked questions: neurological surgery. Accessed May 6, 2020. https://www.acgme.org/Portals/0/ PDFs/FAQ/160_NeurologicalSurgeryFAQs_2017-07-01. pdf?ver=2017-08-18-090725-277

\section{Disclosures}

Dr. Woodrow: consultant for Stryker Spine.

\section{Author Contributions}

Conception and design: all authors. Acquisition of data: Miller, 
Lundy. Analysis and interpretation of data: all authors. Drafting the article: Miller. Critically revising the article: all authors.

Reviewed submitted version of manuscript: all authors. Approved the final version of the manuscript on behalf of all authors:

Miller. Statistical analysis: Miller, Woodrow. Study supervision: Woodrow.

\section{Supplemental Information}

\section{Online-Only Content}

Supplemental material is available with the online version of the article.
Supplemental Figure A. https://thejns.org/doi/suppl/10.3171/ 2020.4.JNS20618.

\section{Correspondence}

Christopher Miller: University of Kansas School of Medicine, Kansas City, KS. cmiller5@kumc.edu. 